\title{
Editorial for the January 2012 Issue of Transport in Porous Media
}

\author{
Martin Blunt
}

Published online: 24 November 2011

(C) Springer Science+Business Media B.V. 2011

It is a great honour for me to assume the Editorship of Transport in Porous Media. This is the leading journal that specializes in research on all types of behaviour in porous systems. Since its formation in 1986, it has witnessed many exciting new developments and an explosion in the range of applications studied.

I would like to thank the founding Editor Professor Jacob Bear whose devotion to this journal has helped establish transport in a porous media as a distinct and rigorous scientific discipline. The link with the Interpore Society further strengthens the field, helping to bring together researchers with common interests.

Many of the greatest global technological and societal challenges facing us this century are related to the sustainable use of water and energy. The underpinning science concerned with these challenges involves the flow, transport and reaction of fluids in porous media applied to, for instance, contaminant clean-up, improved oil and gas recovery and geological storage of carbon dioxide. In addition, many growing scientific fields, such as bioengineering and fuel cell research involve the design and study of porous media processes. The scope of the journal must encompass all these areas.

Despite this huge range of important applications, the fundamental basis of the discipline is still an active field of research. In addition, the range of new and significant applications has led to an explosion of new ideas and the development of innovative mathematical, numerical and experimental techniques to study a fascinating range of phenomena in porous media.

My vision is for Transport in Porous Media to maintain and grow its reputation as the leading journal, publishing fundamental research advances in this rich and exciting field. I hope that I will be able to continue the success of the journal during my time as Editor.

You will notice that we have added new Associate Editors and I would like to welcome them to the journal. They will handle all submissions, and will help ensure fair, rigorous and timely reviews, allowing the rapid publication of novel research papers of the highest quality.

M. Blunt $(\varangle)$

Imperial College, London, UK

e-mail:m.blunt@imperial.ac.uk 